\title{
Transluminal versus Subintimal Angioplasty for Management of Critical Limb Ischemia Patients with Femoropopliteal Occlusive Disease
}

Nehad Foad, Waleed Eldaly, Foad Saad Eldin and Baker Ghoneim*

Faculty of Medicine, Cairo University, Al Manial-11562, Cairo, Egypt

*Corresponding author: Baker Ghoneim, Faculty of Medicine, Cairo University, Al Manial-11562, Cairo, Egypt, Tel: 00201221089311; E-mail: bakerghoneim@kasralainy.edu.eg

Rec date: Jul 04, 2015; Acc date: Aug 22, 2015; Pub date: Aug 24, 2015

Copyright: (c) 2015 Foad N, et al. This is an open-access article distributed under the terms of the Creative Commons Attribution License, which permits unrestricted use, distribution, and reproduction in any medium, provided the original author and source are credited.

\begin{abstract}
Aim

Comparison between intraluminal and subintimal angioplasty with review of technique, factors affecting the success and complications with special emphasis on factors that could predict the wire route meanwhile using simple techniques.

\section{Methods}

This is a non-randomized study with prospectively collected data that included 159 patients presented from 2011 to 2014 to the vascular surgery department with critical chronic lower limb ischemia due to atherosclerotic femoropopliteal occlusive disease for whom percutaneous angioplasty was done. Patients presenting with nonsalvageable limbs requiring primary major amputation and non-atherosclerotic causes of CLI were excluded.

\section{Results}

$75.5 \%$ of the lesionswere crossed transluminally while $19.5 \%$ of the lesions were crossed subintimally. In 8 cases (5\%) the lesion could not be passed. The overall technical success to pass the lesion was $95 \%$. On 24 months follow up, 1ry patency, 2ry patency, limb salvage in intraluminal group are $56.8 \%, 60.2 \%$ and $66.1 \%$ respectively while in subintimal group $46.7 \%, 46.7 \%$ and $60 \%$ respectively. Subintimal was more in the TASC D, lesion more than 10 $\mathrm{cm}$ and in contralateral access ( $\mathrm{P}$ value was $<0.05)$. There were no statistically significant differences between intraluminal and subintimal angioplasty regarding the outcome (Patency and limb salvage).

\section{Conclusions}

The passage of the wire is affected by length of the lesion, the TASC II classification of the lesion and access site with the subintimal passage was more in Lesion more than $10 \mathrm{~cm}$, TASC D lesions and in contralateral access. These factors can be used prospectively as predictors for passage of the wire whether intraluminal or subintimal. In spite of the technical differences between the intraluminal and subintimal passage, yet they show no significant statistical differences regarding the outcome (patency and limb salvage). Hence both should be used as part of vascular armamentarium for revascularization in such frail patients.
\end{abstract}

Keywords: Critical limb ischemia; Limb salvage; Femeropopliteal disease; Subintimal angioplasty

\section{Introduction}

Critical limb ischemia (CLI) is characterized by multi-level disease, high burden of co-morbidity and limited life span. The care of patients with CLI is not easy for the reason that many of them have considerable co-morbidities [1].

Successful revascularisation decreases the major amputation rate in patients with critical limb ischemia (CLI). The effectiveness of peripheral bypass grafts and percutaneous transluminal angioplasty in accomplishing limb salvage has been known [2]. Femoropopliteal segment involvement in occlusive peripheral arterial disease is extremely common and, in one series, was present in $80 \%$ of symptomatic patients underwent angiography. However; the optimal approach for treating this artery is still debated $[3,4]$.

The recent technologic advances in endovascular therapy have extended the applicability of minimally invasive treatment for challenging superficial femoral artery lesions that were previously deemed inappropriate for endovascular therapy. Current infrainguinal endovascular options include balloon angioplasty, subintimal angioplasty, angioplasty with selective stenting, and primary stenting. Several trials have been published; however, the debate continues about which endovascular treatment is preferable [5].

In our protocol for the treatment of all patients with TransAtlantic Inter-Society Consensus (TASC) criteria of CLI, PTA is the first choice revascularization procedure. In this study, we review the efficacy of 
angioplasty in the femoropopliteal segment with special emphasis on the role of selective stenting. We try to compare between intraluminal and subintimal angioplasty with special emphasis on technique, factors affecting the success and complications. We try to review specifically the role of subintimal angioplasty and difficulties specific to the femoropopliteal segment is included with the use of simple techniques.

\section{Patients and methods}

Patient selection: This study is a prospective, non-randomized study performed at the Department of Vascular Surgery in Cairo University hospitals along the period of two years. The study group included patients suffering from critical limb ischemia due to atherosclerotic occlusive disease affecting the femoropopliteal segment. Patients were eligible for enrollment in the study when they complied with all general inclusion criteria, all angiographic inclusion criteria and when none of the exclusion criteria were met. After verification of the inclusion and exclusion criteria, written informed consent for the collection of personal medical data was obtained for each patient before enrollment in the study. The inclusion and exclusion criteria are shown in Table 1.

\begin{tabular}{|c|c|}
\hline \multirow[t]{3}{*}{ Inclusion criteria } & Patients with critical limb ischemia (Patient presents a score of 4 to 6 after Rutherford classification). \\
\hline & Patient is willing to comply with specified follow-up evaluations at the specified times. \\
\hline & Patient (or his or her legal representative) understands the nature of the procedure and provides written informed consent. \\
\hline \multirow[t]{4}{*}{ Angiographic inclusion criteria } & The target lesion is located within the native femoropopliteal artery with or without any other lesions in the arterial tree. \\
\hline & The target lesion has angiographic evidence of stenosis or restenosis $50 \%$ or more or occlusion. \\
\hline & Target vessel diameter visually estimated is between $4 \mathrm{~mm}$ and $6.5 \mathrm{~mm}$. \\
\hline & There is angiographic evidence of at least one vessel runoff to the foot. \\
\hline \multirow[t]{9}{*}{ Exclusion criteria } & Severe renal impairment. \\
\hline & Patients for whom antiplatelet therapy, anticoagulants, or thrombolytic drugs are contraindicated. \\
\hline & Patients with uncorrected bleeding disorders. \\
\hline & Life expectancy of 12 months or less. \\
\hline & Any patient considered to be hemodynamically unstable at onset of the procedure. \\
\hline & Patients suffering from non-atherosclerotic occlusive disease e.g., arteritis \& entrapment syndrome. \\
\hline & Patients with absent runoff. \\
\hline & Patients with associated aortoiliac disease. \\
\hline & Fit patient TASC D with available vein \\
\hline
\end{tabular}

Table 1: Inclusion and Exclusion criteria.

Chronic critical lower limb ischemia was defined following the TASC II guidelines as: lower limb with more than two weeks of rest pain, ulcers, or tissue loss attributed to arterial occlusive disease [6].

Patients presenting with non-salvageable limbs requiring primary major amputation and non-atherosclerotic causes of CLI were excluded from this study. The decision of amputation was taken on basis of severe tissue loss when whole foot lost and non reconstructable arterial occlusion after adequate study either by angiography or CTA.

Endovascular treatment was the first choice modality of treatment in revascularization of all patients. Open surgery was offered selectively for patient whom endovascular failed or complicated and for long TASC II D lesions in fit patients according to American Society of Anesthesia (ASA) score. Surgery was preferred in extensive disease (occlusions of whole length of the SFA and also upper popliteal occlusion and runoff on lower pop in fit patient and available vein).

Pre-procedure assessment: All patients were subjected to history taking, meticulous physical examination and radiological imaging
(Duplex was done in all patients and selectively done CT angiography).

Consent: Detailed explanation of the procedure, its indications, methods, risks\& outcome was done. After which an informed consent was signed by all included. Approval from ethical committee in Cairo University (General surgery department committee) was taken before the beginning of the study.

Technique: All endovascular procedures were done in our angiosuite under local anesthesia. Antegrade, ipsilateral common femoral artery puncture is the preferred access. Contralateral femoral puncture and perform a cross over technique was used when the lesion is very close (less than $2 \mathrm{~cm}$ ) to the SFA origin, obesity and in hostile groin. Retrograde ipsilateral puncture of the popliteal artery \& brachial access were also used in selected cases. After gaining access, an initial diagnostic angiogram was done.

The standard tools for recanalization of stenoses and occlusions consisted of a hydrophilic guidewire and an angled-tip catheter, e.g., Berenstein. Once the lesion has been crossed, the catheter was 
Citation: Foad N, Eldaly W, Eldin FS, Ghoneim B (2015) Transluminal versus Subintimal Angioplasty for Management of Critical Limb Ischemia Patients with Femoropopliteal Occlusive Disease. J Health Edu Res Dev 3: 132. doi:10.4172/2380-5439.1000132

Page 3 of 8

advanced beyond the lesion, the wire removed and contrast injected to ensure that the catheter is within the lumen.

Intralumina or subintimal passage of the wire was not intended from the start rather after passage the shape of the wire and site of reentry judge whether the passage was intraluminal or suintimal. In our study we are aiming to use the simplest devices due to a financial issues and no reentry devices were used nor available.

If a stent is indicated, a self-expanding stent was used. The stent was oversized by $1 \mathrm{~mm}$ relative to the diameter of the SFA. The stent should be long enough to cover the lesion with $5-10 \mathrm{~mm}$ coverage of the normal artery on either side of the lesion.

The procedure outcome: The outcome was evaluated for every case immediately post-procedure, and 3,6,12,18 and 24 months later. Immediate evaluation was based on clinical assessment (pulse, capillary refill, and warmth) and angiography. Follow up was according to clinical re-assessment and duplex. The success of the procedure was determined by the following:

Angiographic success defined as good flow with less than $30 \%$ residual stenosis at the narrowest point of the arterial lumen.

Technical success: was diagnosed by patent completion angiography and clinical retrieval of distal pulse

Clinical success, which may be: Definitive success in the form of regain of pulse.

Clinical improvement (good capillary circulation, warmth, relief of symptoms and good healing of ulcer or minor amputation).

Primary endpoint: technical success, primary patency, secondary patency

Secondary end point: limb salvag, disappear of the rest pain and wound healing

Follow up: clinical success was diagnosed by clinically presence of distal pulse, improvement of patient symptoms and healing of tissues imaging: duplex was done routinely for all patients on their follow up

Data collection and statistical analysis: Double-data entry was performed in an electronic database to generate descriptive data summaries. Data were statistically described in terms of mean \pm standard deviation $( \pm S D$ ), median and range, or frequencies (number of cases) and percentages when appropriate. Comparison of numerical variables between the study groups was done using Student $t$ test for independent samples. For comparing categorical data, Chi square $\left(\chi^{2}\right)$ test was performed. Exact test was used instead when the expected frequency is less than 5. p values less than 0.05 was considered statistically significant. All statistical calculations were done using computer programs SPSS (Statistical Package for the Social Science; SPSS Inc., Chicago, IL, USA) version 15 for Microsoft Windows. All periprocedural and post procedural complications were evaluated and documented

\section{Results}

Over 2 years, 159 patients (159 limbs) with symptomatic femoropopliteal arterial occlusive disease met the inclusion criteria. Among the 159, 61.6\% were male (98 patients).

Demographic features and associated co morbidities are shown in Table 2. Diabetes and hypertension were the main associated co morbidities in both groups. Presenting symptoms were shown in Table
3. The main presenting symptoms were tissue loss in both groups. Lesion morphology and TASC II classification were shown in Tables 4 and 5. Most of lesions were more than $10 \mathrm{~cm}$ in length and TASC c and $\mathrm{D}$ in both groups.

\begin{tabular}{|c|c|c|}
\hline $\begin{array}{l}\text { Risk factors \& co- } \\
\text { morbidities }\end{array}$ & $\begin{array}{l}\text { Intraluminal } \quad \text { No } \\
120(\%)\end{array}$ & $\begin{array}{l}\text { Subintimal No } 31 \\
(\%)\end{array}$ \\
\hline Mean age & 58 & 65 \\
\hline Male & $77(64.2 \%)$ & $15(48.4 \%)$ \\
\hline diabetes & $116(96.7 \%)$ & $26(83.9 \%)$ \\
\hline HTN & $98(81.5 \%)$ & $27(87.1 \%)$ \\
\hline smoking & $68(56.7 \%)$ & $16(51.7 \%)$ \\
\hline Cardiac & $37(30.8 \%)$ & $17(54.9 \%)$ \\
\hline COPD \& asthmatic & $2(1.6 \%)$ & $1(3.2 \%)$ \\
\hline Renal disease & 0 & $1(3.2 \%)$ \\
\hline Stroke & $6(5 \%)$ & $4(13 \%)$ \\
\hline
\end{tabular}

Table 2: Risk factors.

\begin{tabular}{|l|l|l|}
\hline Clinical presentation & Intraluminal No 120 (\%) & Sub intimal No 31 (\%) \\
\hline Rutherford IV & $32(26.7 \%)$ & $5(16.1 \%)$ \\
\hline Rutherford V & $66(55 \%)$ & $14(45.2 \%)$ \\
\hline Rutherford VI & $19(15.8 \%)$ & $12(38.7 \%)$ \\
\hline
\end{tabular}

Table 3: Clinical presentation.

\begin{tabular}{|l|l|l|}
\hline TASC II & Intraluminal No 120 (\%) & Sub intimal No 31(\%) \\
\hline A & $14(11.7)$ & 0 \\
\hline B & $35(29.2)$ & $2(6.5 \%)$ \\
\hline C & $23(19.2)$ & $2(6.5 \%)$ \\
\hline D & $48(40 \%)$ & $27(87.1 \%)$ \\
\hline
\end{tabular}

Table 4: TASC classification.

\begin{tabular}{|l|l|l|}
\hline Lesion Length & Intraluminal No 120 (\%) & Sub intimal No 31 (\%) \\
\hline Less than $5 \mathrm{~cm}$ & $39(32.5 \%)$ & $2(6.5 \%)$ \\
\hline Between 5 and $10 \mathrm{~cm}$ & $24(20 \%)$ & $2(6.5 \%)$ \\
\hline More than $10 \mathrm{~cm}$ & $57(47.5 \%)$ & $27(87.1 \%)$ \\
\hline
\end{tabular}

Table 5: lesion length.

Runoff vessels analysis shows that 68 patients had 3 vessels runoff (42.8\%), 11 patients had 2 vessels runoff (6.9\%) and 80 patients with single runoff (50.3\%).

Subintimal was more in the TASC D, lesion more than $10 \mathrm{~cm}$ and in contralateral access (P value was $<0.05$ ). As shown in Table 6, SI was more in the cases where contralateral access used. 


\begin{tabular}{|l|l|l|}
\hline $\begin{array}{l}\text { Access } \\
\text { Used }\end{array}$ & Intraluminal No 120 (\%) & Sub intimal No 31 (\%) \\
\hline Ipsilateral & $103(85.8 \%)$ & $16(51.7 \%)$ \\
\hline Contralateral & $16(13.3 \%)$ & $12(38.7 \%)$ \\
\hline Other & 1 brachial $(0.8 \%)$ & 3 contralateral and popliteal $(9.7 \%)$ \\
\hline
\end{tabular}

Table 6: Access used.

$75.5 \%$ of the lesions (120 cases) were crossed transluminally while $19.5 \%$ ( 31 cases) of the lesions were crossed subintimally. In 8 cases (5\%) the lesion could not be passed. The overall technical success to pass the lesion was $95 \%$.

The mortality rate was $1.3 \%$ (only 2 cases). The complications were present in 56 patients (37\%). The complications were summarized in Table 7. All access hematomas were mild to moderate in size and were treated conservatively. Dissections were evaluated and were stented if they are flow limiting only. The 2 cases with recoil necessitated stenting.

\begin{tabular}{|l|l|l|l|l|}
\hline \multirow{2}{*}{ Complication } & \multicolumn{2}{l|}{ Transluminal } & \multicolumn{2}{l|}{ Subintimal } \\
\cline { 2 - 5 } & Number & Percent & Number & Percent \\
\hline Access hematoma & 2 & $1.3 \%$ & 0 & - \\
\hline Dissection & 28 & $18.5 \%$ & 20 & $13.2 \%$ \\
\hline Recoil & 0 & - & 2 & $1.3 \%$ \\
\hline Perforation & 1 & $0.7 \%$ & 0 & - \\
\hline Thrombosis & 1 & $0.7 \%$ & 2 & $1.3 \%$ \\
\hline Angina & 1 & $0.7 \%$ & 0 & - \\
\hline
\end{tabular}

Table 7: Complications.

Twelve cases were excluded from the study including the 8 failed to cross the lesion, 3 cases complicated with acute thrombosis and open surgery was done, and one case had acute angina on table so the intervention was aborted and the patient transferred to ICU and the limb died so primary amputation was done. 145 patients completed the 6 months follow up, 135 patients completed the 12 months follow up and 92 patients completed the 24 months follow up.

As shown in Figure 1, On 24 months follow up, 1ry patency, 2ry patency, limb salvage in intraluminal group are $56.8 \%, 60.2 \%$ and $66.1 \%$ respectively while in subintimal group $46.7 \%, 46.7 \%$ and $60 \%$ respectively. ( $\mathrm{P}$ value $<0.560$ ).

\section{Discussion}

Although SIA is currently widely used and worldwide experience with the technique is growing, there is still considerable doubt regarding the method and its results. This is mainly due to lack of evidence from randomized clinical trials comparing SIA with intraluminal angioplasty. However, SIA is known to yield high percentages of technical success and acceptable long-term clinical patency and limb-salvage rates.

The comparison between subintimal and intraluminal is difficult and unfair as both are used in different situations as regard the patency rate. But we tried to point out the predictors for subintimal angioplasty that can be used in the future.

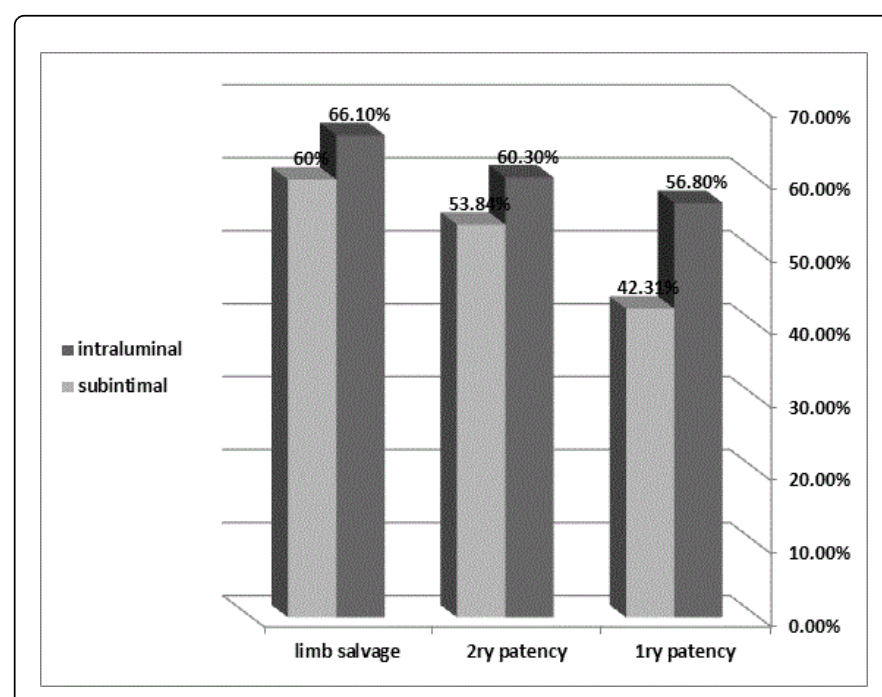

Figure 1: On 24 months follow up.

First, the lesion morphology after angioplasty is different. The atherosclerotic plaque remains in the flow channel after intraluminal angioplasty, whereas a subintimal flow channel is devoid of exposed plaque except at entry and re-entry points. This could alter arterial wall remodeling after SIA from those observed with IBA. Hence, the role of neo-intimal hyperplasia after stent placement in a subintimal channel is unknown. Second, the types of lesions in each group are different. Whereas intraluminal angioplasty can be used for segments with stenosis or short occlusions, subintimal angioplasty is used for segments with short or long occlusions. Also, as suggested by the worsening stent results with increasing TASC lesion, the majority of SIA are performed for TASC C and D lesions.

In 2013, Antoniou and coauthors published a meta-analysis of endovascular versus surgical reconstruction of femoropopliteal arterial disease including a total of 2817 patients (1387 open, 1430 endovascular). Comparing our patient's demographic characteristics, risk factors and co-morbidities to those of patients in their metaanalysis, we will find that gender was almost the same while our mean age was lower [8-11]. Regarding the risk factors, $91.2 \%$ of our patients were diabetics compared to only $43 \%$ in Antoniou et al. other risk factors were almost the same. Our lower mean age may be attributed to that all our patients suffer from |CLI and $90 \%$ were diabetic and this reflect the burden of comorbidities with higher mortalities. Increased life stress and obesity predispose to our high incidence of diabetes in Egypt. All of the cases included in our study presented with critical limb ischemia and about $75 \%$ of them tissue loss. Moreover, about $57 \%$ of the cases had lesions more than $10 \mathrm{~cm}$ in length, about $62 \%$ of the cases chronic total occlusion was found, and this can be explained by that all of our cases had critical limb ischemia. As many of our patients were diabetic and diabetes is characterized by extensive and distal vessels disease that may explain the high number of tissue loss in our study. It is commonly documented that a more severe state of the limb, especially Rutherford 6 with ulcer or gangrene are more likely results in a higher major amputation rate. The need for major amputation is twofold higher in patients with ulcers or gangrene than 
in patients with only rest pain as severe tissue loss reflects the great load of the disease [12].

It is noticed that in lesions less than $10 \mathrm{~cm}$ length, the wire usually passed transluminally, but in lesions more than $10 \mathrm{~cm}$ in length the wire passed subintimally in a considerable percent of cases (about one third of the cases with lesion length more than $10 \mathrm{~cm}$ the wire passed subintimally with significant $\mathrm{P}$ value $(\mathrm{P}$ value $<0.05)$. Vraux et al. have reported that the length of the occlusion $(>10 \mathrm{~cm})$ is a predictor of $\mathrm{SA}$ technical success and patency [13]. Baril et al. in 2010 stated that endovascular interventions for TASC II D lesions can be safely performed with excellent hemodynamic improvement and limb salvage rates [14]. Arterial calcification, poor runoff, diabetes, treatment for chronic limb ischemia as opposed to claudication, and lesion length are the variables most frequently postulated to affect patency. Some articles suggest that calcification in the wall of the occluded artery makes recanalization difficult and predisposes to technical failure, but others could not confirm this effect. Although intuitively, occlusions are thought to be more difficult to treat than stenosis, results have been conflicting. All of our patients were treated for chronic limb ischemia, and we found primary patency to be $18 \%$ at 3 years [15]. Noticing that most of our patients were diabetics where Vascular calcifications are usually severe and diffuse, and arterial occlusive disease occurs mainly at the level of the infrapopliteal arteries, impairing runoff vessels and, thus, reducing chances and success of intervention [16]. Also the risks of intervention are usually higher in the diabetic population due to the comorbidities [17].

We classified the lesions according to the TASC II classification, and more than $50 \%$ of the cases were TASC II D lesions. Moreover, subintimal passage of the wire was observed in cases with lesions classified as TASC II D and also that was found to be statistically significant. ( $\mathrm{P}$ value $<0.05)$. The high percentage of TASC D cases reflect that the CLI to occur need extensive disease and long occlusion not simply short stenosis or occlusion and the same time reflect the difficulties in management of such difficult lesions and the technical success of PTA and could be used as the 1st choice [18]. However it was mentioned by Bakken et al. and Lida et al. that TASC A \&B can cause CLI as diabetic patient had in addition microvascular deficiency (microangiopathy) because the presence of DM appears to reduce blood flow to the microvascular bed via arterio-venous fistulae leading to symptomatic disease with less advanced femero-popliteal disease $[11,12]$. Regarding the runoff vessels about $50 \%$ of our cases had single runoff vessel and this is may be due to the fact that more than $90 \%$ of our patients were diabetics. While the average percent of patients suffering from critical limb ischemia in the meta-analysis done by Antoniou et al. was 66\% [8]. This may reflect the difficulties in management of our patients [19]. Poor peripheral runoff is also associated with poorer long-term results. Long-term patency rates of $30 \%$ in limbs with poor runoff, versus $52 \%$ with good runoff [20].

We used the ipsilateral femoral access as the first option whenever it was possible. The second option was the contralateral femoral approach. In one case only we used the brachial access as the lesion was flush to the SFA and the patient had chronic total occlusion of the common iliac artery in the contralateral limb and it was a symptomatic. In 3 cases we had to use the ipsilateral popliteal approach due the failure to pass the lesion via the femoral approach.

This study did not use several other techniques described for use in difficult passage for long femoropopliteal lesions. Retrograde passage through popliteal access has been used mainly for flush SFA occlusions if contralateral approach was failed. Usually the retrograde puncture of the popliteal artery was done by using duplex ultrasonography, and SIPTA is performed from the distal SFA to the proximal SFA, which is opposite the direction used for the standard approach. The retrograde SFA SI-PTA approach has a reported patency rate of $62 \%$ at 1 year [21].

This study also did not use the technique described by Balas et al. which approaches flush occlusions of the SFA with a combination of open surgery and endovascular techniques [22].

Regarding the passage of the wire, in about $75.5 \%$ of the cases the wire passed transluminally while in only about $19.5 \%$ of the cases the wire passed subintimally. Although it was mentioned by Lazaris et al. that Subintimal angioplasty is a different technique to transluminal angioplasty; not only are there technical differences but also because SA achieves recanalization of long arterial occlusions which PTA cannot and they argued that in transluminal angioplasty selection on anatomical ground is important because the ideal patient will be the one with focal disease. However because of the presence of diffuse disease in chronic CLI, transluminal angioplasty is only applicable in a small proportion of CLI patients. In contrast, SA due to its effectiveness in long occlusions can be applied to most patients with CLI. Consequently SA can be considered as an alternative to open surgery for these patients. The treatment is relatively atraumatic, complications are rare and in most cases treated by endovascular techniques.

Hynes et al. have reported the number of attempted revascularisations to have doubled since the introduction of the subintimal angioplasty [23]. Awad et al. used the subintimal technique routinely in all femoropopliteal occlusions, whereas stenoses were usually treated intraluminally [24]. Antusevas et al. in 2008 found that Results from subintimal angioplasty of superficial femoral artery occlusions was superior to the results of PTA. Subintimal angioplasty has also provided a new method of managing occlusions, which has substantially improved the entire field but specifically has changed lower extremity revascularization [25].

Since long complex lesions are usually present in CLI patients, successful endovascular recanalisation of the SFA can sometimes only be performed with subintimal angioplasty (SIA). SIA has been associated with high limb salvage rates between $85 \%$ and $90 \%$ at 1 year, even despite a low 50\% 1-year primary patency rate [26].

These results were recently confirmed by Bolia et al. and Setacci et al. with primary success rates of $80 \%$ and $83.5 \%$ and limb salvage rates of $85 \%$ and $88 \%$ at 1 year, respectively [27-29].

In a study done by Köchera, et al. in 2010 aiming at retrospective assessment in mid-term outcomes of subintimal angioplasty of chronic arterial occlusions in femoro-popliteal region, Technical success was achieved in $86.46 \%$. Primary patency rate was $83.1 \%, 67.5 \%, 58 \%$ and $48.4 \%$ at $6,12,24$ and 36 months respectively and the study concluded that subintimal recanalisation is a simple and safe procedure for treatment of chronic peripheral arterial occlusions with high primary technical success rate, acceptable primary patency rate, low percentage of complications and mortality is as low as nil. Subintimal angioplasty is definitely advantageous and fast method in patients with critical limb ischemia with high possibility of limb salvage [30].

PSA offers a number of advantages meanwhile in terms of the technique, no specialized equipment or materials are necessary. It does not require extensive experience by the operators, the procedure is inexpensive, and it is relatively non-traumatic and does not preclude 
subsequent surgery should it fail to recanalize an occlusion. It is applicable in a large number of situations where other techniques are likely to fail, for example in long occlusions, moderately calcified vessels, previously failed intraluminal approach and in hard occlusions of long standing. For long occlusions of the tibial artery, flush SFA occlusion, popliteal occlusions extending into the trifurcation, in the presence of a large proximal collateral, common femoral occlusions extending into the bifurcation, and when a perforation occurs in an attempted SFA recanalization, PSA is probably the only technique that allows a successful outcome to be achieved in the vast majority of cases. It was the hope for patients who are poor candidates for general anaesthesia or who do not have an adequate vein conduit for a distal bypass may be successfully treated. The procedure rarely compromises a subsequent surgical option in case of a failed angioplasty, and is also more readily repeatable compared to surgery [31].

However, there is a serious disadvantage of PSA, which may make the patient worse rather than better. There is a potential risk of damage to important collaterals distal to the occlusion when these are included in the dissected portion. When important collaterals are compromised without achieving a haemodynamically viable channel in the main artery, the patient's distal circulation will be compromised and urgent bypass surgery will be required to restore circulation to the distal leg. It is therefore crucially important that a dissection is not extended too far distal to the occlusion, particularly early on in a doctor's experience [31]. But in a study done by Treiman et al. where they do support the concept that failed recanalization does not alter or jeopardize subsequent bypass [15].

In the current study, The overall technical success to pass the lesion was $95 \%$. Antoniou et al. reported $91 \%$ technical success in the endovascular group with no significant heterogeneity among the studies. It should be noticed that the meta-analysis included studies done many years ago and nowadays with the rapid development of endovascular tools and their quality we think that 95\% technical success using the simplest endovascular tools for treating critical limb ischemia patients is satisfactory [8]. In a study done by Myers and coworkers shows similar rate, The initial technical success rate of $92.6 \%$ and the patency rate of $82.3 \%$ at 6 months [23]. Sidhu et al. mentioned that severe calcification was the predominant cause of failure, as it is difficult to reenter the distal lumen. Also, The absence of a proximal SFA stump presents difficulty in initiating the subintimal plane, which is another cause for technical failure [32].

The nature of the lesion affects both the success rate and the longterm patency: more distal and longer lesions are more technically challenging and less likely to stay open, and the presence of calcification is associated with a lower success rate. The major causes of technical failure in SIA are failure of reentry and elastic recoil [33].

The overall primary patency rate in our study at 12 months was $54.7 \%$ in comparison to about $62 \%$ in three randomized trials and four observational studies and this inferior result may be due to the fact that most of our patients were diabetic with TASC II C or D category and with long total occlusions [8].The primary patency rate at 12 months for the transluminal approach was $56.8 \%$, while for the subintimal approach was $46.7 \%$, so there was no statistical significance between the two approaches ( $\mathrm{P}$ value 0.55 ).

In the study of Sidhu et al. the cumulative primary patency at 6 and 12 months was $90 \%$ and $73 \%$, respectively and Primary patency of SA is lower compared to surgical bypass, especially that with autogenous vein. However, patency can be maintained with secondary procedures with little additional morbidity or mortality. Therefore, SA can be considered a primary procedure even in patients with TASC II C/D lesions. It is important to avoid damage to the target outflow vessel thereby preserving future options for operative revascularization. The secondary patency rate at 6 and 12 months was $94 \%$ and $85 \%$, respectively [32].

Norgren et al. reported that the 1 year primary patency after PTA alone for the femoropopliteal segment occlusive lesions is $77 \%$ for the stenosis only and $63 \%$ for occlusions. Regarding the 1 year primary patency of PTA and stenting for the femoropopliteal lesions they reported 1 year primary patency of $75 \%$ for the stenosis and $73 \%$ for the occlusions [6]. Data regarding primary patency rates at 1 year after SIA vary widely. A recent meta-analyses of several SIA studies, including 1549 and 2810 limbs, respectively, estimated that 1-year primary patency rate was approximately $50 \%$. Limb salvage is the most widely accepted clinical outcome measure in the CLI population [33-38]. The overall limb salvage in our study was $64.9 \%$ and the reason beneath the fact that the limb salvage is higher than patency rates is that all of the cases had critical limb ischemia and endovascular intervention may provide sufficient blood supply needed for healing then by the time the vessels is occluded the demand of blood supply is decreased and the collateral developed is enough for the tissue viability. The limb salvage at 12 months for the transluminal approach was $66.1 \%$, while for the subintimal approach was $60 \%$, so there was no statistical significance between the two approaches ( $\mathrm{P}$ value 0.58 ).

In our study we just used the simplest endovascular tools. Evolving endovascular strategies embrace new technologies in an attempt to improve the safety and efficacy of revascularization procedures for lower extremity arterial occlusive disease. Drug-eluting stents and drug coated balloons, and the use of stent grafts are currently being evaluated in the primary treatment of femoropopliteal segment disease for selected patients. Research on polymer-based and alloy-based bioabsorbable stents is a promising field, which, if substantiated, may change endovascular treatment paradigms. Such novel treatments along with the imperative understanding of medical treatment focused on the individual patient's needs and expectations may constitute areas of future research [8].

Regarding the complications the mortality rate was $1.3 \%$ and the overall complication rate was $37 \%$. It is noticed that in our study there is a high percent of dissection (about 31\%) and this is may be due to the fact that more than half of our cases are TASC II D and more than $90 \%$ of our cases are diabetics leading to the presence of heavily calcifications.

There is an explanation mentioned by Giles et al. rationalize the high rate of complications observed in endovascular group that the patients who preferentially undergo a percutaneous intervention tend to be sicker than patients in whom bypasses are the first line of treatment. An attempt at percutaneous intervention may be per formed as a "salvage" procedure in patients who have limited life expectancies and extensive comorbidities who would have otherwise undergone a primary amputation, which is associated with perioperative mortality rates of $5 \%$ to $17 \%$ Although the minimally invasive nature of infrapopliteal PTA has obvious appeal, it also has potential disadvantages. These may include conversion of an elective to emergency procedure, loss of bypass targets, a less durable solution, lengthy procedures causing excessive radiation exposure, and the potential for rising costs of care if multiple interventions are necessary. The delay to surgery caused by an inadequate or failed intervention could cause in-creased ischemia and lead to worsening wounds, minor 
amputations, and even limb loss, despite the ability to construct a durable bypass graft [39-42].

On the contrary, in a study done by Faglia et al. the survival of amputated patients who had previously undergone revascularization was significantly better than that of non revascularized amputees, even when unable to avoid major amputation. In addition to already demonstrated that this revascularization reduces the rate of major amputation. Moreover, our data indicated that the rate of below-theknee amputation in PTA patients was significantly higher than that of nonrevascularized patients, as well as than that of amputated patients because of BPG closure. The outcomes of below-the-knee amputation are superior to those of the above-the-knee amputation. They further encourage performing revascularization in all diabetic patients with CLI [18].

In metaanalysis done by Markos et al. Overall complication rates of SIA are reported as between $6 \%$ and $17 \%$. Definitions of complications differ widely, and there is very limited evidence about factors affecting the complication rate. The complication rate of SIA is no higher than for PTA, and the risk of major adverse events is lower in SIA than surgery. The amputation rate after SIA was reported as $2.2 \%$ in patients with CLI [43].

\section{Limitation of Study}

\section{Study limitation}

There are some limitations of the present study. First, this is non randomised study. Therefore, there may be a bias in selection of patients.

Second, the results of the present study were derived from a singlecenter experience with a high work volume where certain techniques have been routinely adopted for many years as a first choice. It is therefore likely that the selection of techniques with its own limitations may differ largely from centers with another experience.

Third, in most of our patients computed tomographic angiogram or a magnetic resonance angiogram was not a baseline performed before the intervention. An extensive use of these diagnostic tools might have impact on the decision process.

Fourth, we have economic problem that hinder us from using the more recent technology as reentry devices and special recanalization device. But this is may be a point of power that we are obliged to seek less costly techniques to overcome this factor.

In addition, this study included treated segments from the proximal SFA to the tibial vessels. This heterogeneous data could make interpretation of outcomes more difficult.

Finally, we have lost patients follow up. This may be attributed to socioeconomic factors and lack of proper insurance system. So the lower mortality rate in this study cannot be taken with certainty.

\section{Conflict of Interest}

Non

\section{Conclusions}

The passage of the wire is affected by length of the lesion, the TASC II classification of the lesion and access site with the subintimal passage was more in Lesion more than $10 \mathrm{~cm}$, TASC D lesions and in contralateral access. These factors can be used prospectively as predictors for passage of the wire whether intraluminal or subintimal In spite of the technical differences between the intraluminal and subintimal passage, yet they show no significant statistical differences regarding the outcome (patency and limb salvage). Hence both should be used as part of vascular armamentarium for revascularization in such frail patients.

\section{References}

1. Leng GC, Fowkes FG, Lee AJ, Dunbar J, Housley E, et al. (1996) Use of ankle brachial pressure index to predict cardiovascular events and death: a cohort study. BMJ 313: 1440-1444.

2. Dosluoglu HH, Cherr GS, Lall P, Harris LM, Dryjski ML (2008) Stenting vs above knee polytetrafluoroethylene bypass for TransAtlantic InterSociety Consensus-II C and D superficial femoral artery disease. J Vasc Surg 48: 1166-1174.

3. Bosiers M, Torsello G, Gissler HM, Ruef J, Müller-Hülsbeck S, et al. (2009) Nitinol stent implantation in long superficial femoral artery lesions: 12-month results of the DURABILITY I study. J Endovasc Ther 16: 261-269.

4. Norgren L, Hiatt WR, Dormandy JA, Nehler MR, Harris KA, et al. (2007) Inter-Society Consensus for the Management of Peripheral Arterial Disease (TASC II) Eur J Vasc Endovasc Surg 33.

5. Bradbury AW, Adam DJ, Bell J, Forbes JF, Fowkes FG, et al. (2010) Bypass versus Angioplasty in Severe Ischaemia of the Leg (BASIL) trial: An intention-to-treat analysis of amputation-free and overall survival in patients randomized to a bypass surgery-first or a balloon angioplastyfirst revascularization strategy. J Vasc Surg 51: 5S-17S.

6. Antoniou GA, Chalmers N, Georgiadis GS, Lazarides MK, Antoniou SA, et al. (2013) A meta-analysis of endovascular versus surgical reconstruction of femoropopliteal arterial disease. J Vasc Surg 57: 242-253.

7. Hynes N, Mahendran B, Manning B, Andrews E, Courtney D, et al. (2005) The influence of subintimal angioplasty on level of amputation and limb salvage rates in lower limb critical ischaemia: a 15-year experience. Eur J Vasc Endovasc Surg 30: 291-299.

8. Akbari CM, LoGerfo FW (1999) Diabetes and peripheral vascular disease. J Vasc Surg 30: 373-384.

9. Bakken AM, Palchik E, Hart JP, Rhodes JM, Saad WE, et al. (2007) Impact of diabetes mellitus on outcomes of superficial femoral artery endoluminal interventions. J Vasc Surg 46: 946-958.

10. Lida O, Soga Y, Hirano K, Kawasaki D, Suzuki K, et al. (2012) Midterm Outcomes and Risk Stratification after Endovascular Therapy for Patients with Critical Limb Ischaemia due to Isolated Below-the-knee Lesions. European Journal of Vascular and Endovascular Surgery 43.

11. Vraux H, Hammer F, Verhelst R, Goffette P, Vandeleene B (2000) Subintimal angioplasty of tibial vessel occlusions in the treatment of critical limb ischaemia: mid-term results. Eur J Vasc Endovasc Surg 20: 441-446.

12. Baril DT, Chaer RA, Rhee RY, Makaroun MS, Marone LK (2010) Endovascular interventions for TASC II D femoropopliteal lesions. J Vasc Surg 51: 1406-1412.

13. Treiman GS, Treiman R, Whiting J (2006) Results of percutaneous subintimal angioplasty using routine stenting. J Vasc Surg 43: 513-519.

14. Beckman JA, Creager MA, Libby P (2002) Diabetes and atherosclerosis: epidemiology, pathophysiology, and management. JAMA 287: 2570-2581.

15. Hertzer NR, Bena JF, Karafa MT (2007) A personal experience with the influence of diabetes and other factors on the outcome of infrainguinal bypass grafts for occlusive disease. J Vasc Surg 46: 271-279.

16. Faglia E, Clerici G, Losa S, Tavan D, Caminiti M, et al. (2009) Limb revascularization feasibility in diabetic patients with critical limb ischemia: Results from a cohort of 344 consecutive unselected diabetic patients evaluated in Diabetes research and clinical practice 95 : 364-371. 
Citation: Foad N, Eldaly W, Eldin FS, Ghoneim B (2015) Transluminal versus Subintimal Angioplasty for Management of Critical Limb Ischemia Patients with Femoropopliteal Occlusive Disease. J Health Edu Res Dev 3: 132. doi:10.4172/2380-5439.1000132

Page 8 of 8

17. Sadek M, Faries PL (2010) Infrainguinal Disease: Endovascular Treatment. In Cronenwett JL, Johnston WK, Rutherford's Vascular Surgery Philadelphia: Saunders Elsevier.

18. Schnieder PA (2005) Endovascular surgery management of chronic lower extremity ischaemia. In Rutherford RB, Vascular surgery Philadelphia: Elsevier saunders.

19. McCarthy RJ, Neary W, Roobottom C, Tottle A, Ashley S (2000) Shortterm results of femoropopliteal subintimal angioplasty. Br J Surg 87: 1361-1365.

20. Balas P, Pangratis N, Ioannou N, Milas P, Klonaris C, et al. (2000) Open subintimal angioplasty of the superficial femoral and distal arteries. J Endovasc Ther 7: 68-71.

21. Myers SI, Myers DJ, Ahmend A, Ramakrishnan V (2006) Preliminary results of subintimal angioplasty for limb salvage in lower extremities with severe chronic ischemia and limb-threatening ischemia. J Vasc Surg 44: 1239-1246.

22. Awad S, Karkos CD, Serrachino-Inglott F, Cooper NJ, Butterfield JS, et al. (2006) The impact of diabetes on current revascularisation practice and clinical outcome in patients with critical lower limb ischaemia. Eur J Vasc Endovasc Surg 32: 51-59.

23. Antusevas A, Aleksynas N, Kaupas RS, Inciura D, Kinduris S (2008) Comparison of results of subintimal angioplasty and percutaneous transluminal angioplasty in superficial femoral artery occlusions. Eur J Vasc Endovasc Surg 36: 101-106.

24. Met R, Van Lienden KP, Koelemay MJ, Bipat S, Legemate DA, et al. (2008) Subintimal angioplasty for peripheral arterial occlusive disease: a systematic review. Cardiovasc Intervent Radiol 31: 687-697.

25. Bolia A (2005) Subintimal angioplasty in lower limb ischaemia. J Cardiovasc Surg (Torino) 46: 385-394.

26. Setacci C, Chisci E, de Donato G, Setacci F, Iacoponi F, et al. (2009) Subintimal angioplasty with the aid of a re-entry device for TASC C and D lesions of the SFA. Eur J Vasc Endovasc Surg 38: 76-87.

27. Joels CS, York JW, Kalbaugh CA, Cull DL, Langan EM 3rd, et al. (2008) Surgical implications of early failed endovascular intervention of the superficial femoral artery. J Vasc Surg 47: 562-565.

28. Köcher M, Cerna M, Utikal P, Kozak J, Sisola I, et al. (2010) Subintimal angioplasty in femoropopliteal region-Mid-term results. Eur J Radiol 73: 672-676.

29. Bolia A (2002) Subintimal angioplasty In Leahy AL, Bell PR, Katzen BT (Eds) Minimal Access Therapy for Vascular Disease, London: Taylor et Francis e-Library, pp: 48-91.

30. Sidhu R1, Pigott J, Pigott M, Comerota A (2010) Subintimal angioplasty for advanced lower extremity ischemia due to TASC II C and D lesions of the superficial femoral artery. Vasc Endovascular Surg 44: 633-637.
31. Markose G1, Miller FN, Bolia A (2010) Subintimal angioplasty for femoro-popliteal occlusive disease. J Vasc Surg 52: 1410-1416.

32. Rooke TW (2007) vascular medicine and endovascular interventions. Columbia: Blackwell Futura.

33. Lipsitz EC, Ohki T, Veith FJ, Rhee SJ, Kurvers H, et al. (2004) Fate of collateral vessels following subintimal angioplasty. J Endovasc Ther 11: 269-273.

34. Tefera G, Hoch J, Turnipseed WD (2005) Limb-salvage angioplasty in vascular surgery practice. J Vasc Surg 41: 988-993.

35. Clair DG1, Dayal R, Faries PL, Bernheim J, Nowygrod R, et al. (2005) Tibial angioplasty as an alternative strategy in patients with limbthreatening ischemia. Ann Vasc Surg 19: 63-68.

36. Hynes N, Akhtar Y, Manning B, Aremu M, Oiakhinan K, et al. (2004) Subintimal angioplasty as a primary modality in the management of critical limb ischemia: comparison to bypass grafting for aortoiliac and femoropopliteal occlusive disease. J Endovasc Ther 11: 460-471.

37. Yilmaz S, Sindel T, Ceken K, AlimoÄŸlu E, LÃ¹/4leci E (2001) Subintimal recanalization of long superficial femoral artery occlusions through the retrograde popliteal approach. Cardiovasc Intervent Radiol 24: 154-160.

38. Saketkhoo RR, Razavi MK, Padidar A, Kee ST, Sze DY, et al. (2004) Percutaneous bypass: subintimal recanalization of peripheral occlusive disease with IVUS guided luminal re-entry. Tech Vasc Interv Radiol 7: 23-27.

39. Schneider JR, Verta MJ, Alonzo MJ, Hahn D, Patel NH, et al. (2011) Results with Viabahn-assisted subintimal recanalization for TASC C and TASC D superficial femoral artery occlusive disease. Vasc Endovascular Surg 45: 391-397.

40. Schmieder GC, Richardson AI, Scott EC, Stokes GK, Meier GH 3rd, et al. (2008) Selective stenting in subintimal angioplasty: analysis of primary stent outcomes. J Vasc Surg 48: 1175-1180.

41. Siablis D, Diamantopoulos A, Katsanos K, Spiliopoulos S, Kagadis GC, et al. (2012) Subintimal angioplasty of long chronic total femoropopliteal occlusions: long-term outcomes, predictors of angiographic restenosis, and role of stenting. Cardiovasc Intervent Radiol 35: 483-490.

42. White JV (2010) Lower Extremity Arterial Disease. In J. L. Cronenwett, et W. K. Johnston, Cronenwett: Rutherford's Vascular Surgery.

43. Giles KA, Pomposelli FB, Spence TL, Hamdan AD, Blattman SB, et al. (2008) Infrapopliteal angioplasty for critical limb ischemia: relation of TransAtlantic InterSociety Consensus class to outcome in 176 limbs. J Vasc Surg 48: 128-136. 